\title{
O FILOSOFAR BUDISTA: BREVES REFLEXÕES SOBRE O FAZER FILOSÓFICO E AS SUAS MOTIVAÇÕES
}

\author{
Ana Paula Martins Gouveia* \\ apaulamg@usp.br
}

RESUMO Este texto propõe a trazer à tona alguns aspectos dos estudos do budismo e de sua filosofia no Brasil, que têm sido, de alguma forma, negligenciados ou tratados de modo pouco condizente com a proposta com que este filosofar foi inicialmente concebido. Não se trata de convencer ou "converter" acadêmicos brasileiros a pensarem de maneira similar aos eruditos budistas, mas simplesmente destacar pontos que parecem relevantes para dar continuidade a um debate que já vem sendo estabelecido, particularmente na última década. Com este propósito, serão levantadas questões como as motivações e métodos do fazer filosófico, o dogmatismo, a ética e formas de transmissão de conhecimento.

Palavras-chave Budismo, filosofia, ética, motivação, dogmatismo.

ABSTRACT This text aims to highlight some aspects of the study of Buddhism and its philosophy in Brazil, which have been either neglected or treated in a manner that is incongruous with the proposal upon which this philosophy was initially conceived. The motivation here is not to convince or "convert" Brazilian scholars to think in a similar way to the Buddhist scholars, but simply to bring out points that seem to be relevant to foster the debate that has already been established, particularly in the last decade. For

* Universidade de São Paulo (USP). Artigo recebido em 15/03/2015 e aprovado em 28/08/2015. 
this purpose, issues regarding motivation and method in philosophical work, dogmatism, ethics and modes of knowledge transmission will be raised.

Keywords Buddhism, philosophy, ethics, motivation, dogmatism.

\section{Exórdio}

O texto que se segue não se propõe a ser um artigo acadêmico sobre algum aspecto específico da filosofia budista, mas sim uma espécie de ensaio, um comentário, a respeito da forma como alguns aspectos ligados ao estudo desta filosofia vêm se desenvolvendo no Brasil. Mais do que um aprofundamento verticalizado sobre um tema específico, gostaria de trazer à tona, ou rediscutir, alguns pontos capazes de alimentar a discussão já em andamento sobre o filosofar dentro dos parâmetros budistas, mapeando alguns tópicos relevantes para o debate.

Depois de ter realizado trabalhos de pesquisa nos Estados Unidos e na França, lugares onde este é um campo de investigação acadêmico já consolidado, alguns aspectos relativos à maneira como a área vem se formando no Brasil - e mesmo em outros lugares - chamaram-me a atenção, e é sobre isso que gostaria de refletir. Visto que este exemplar da revista Kriterion dedicase exclusivamente a tal tema e tem a função de "expor", de alguma forma, questões relevantes à área, pareceu-me ser pertinente redigir um comentário que enfatize alguns aspectos fundamentais ao florescimento das pesquisas, nomeadamente: observações sobre pontos de contraste e de contato relativos a como especialistas de outros países trabalham o assunto, e uma retomada ao "quase eterno" tema da comparação entre as chamadas filosofias "ocidentais" e "orientais" - lembrando sempre que a terminologia "ocidental" e "oriental" é bastante complexa, e requer um olhar extremamente crítico. ${ }^{1}$

Como se sabe, por mais que em alguns outros países esta discussão já esteja em estágios bem avançados, aqui no Brasil ela ainda parece engatinhar; mas isso não significa estar parada, posto que estamos dando os primeiros passos. Mesmo que ainda não se tenha, por exemplo, um departamento dedicado exclusivamente a estudos budistas, várias pesquisas de relevância já estão sendo realizadas, basta lembrar, entre outros casos, que a tese de doutorado

1 Como escreve Said: "[...] Orientalismo é, em grande medida, um livro ligado à dinâmica tumultuosa da história contemporânea. Assim sendo, enfatizo que nem o termo 'Oriente' nem o conceito de 'Ocidente' têm estabilidade ontológica; ambos são constituídos de esforço humano - parte afirmação, parte identificação do Outro. O fato de que essas rematadas ficções se prestem facilmente à manipulação e à organização das paixões coletivas nunca foi mais evidente do que em nosso tempo [...]" (2003, p. 13). 
de Ferraro (2012), intitulada “"Verdade ordinária' e 'verdade suprema' como bases dos ensinamentos budistas no pensamento de Nāgārjuna" e orientada por Leonardo Alves Viera na Universidade Federal de Minas Gerais, foi a vencedora do prêmio de melhor tese na ANPOF em 2014. Este fato, que por si só já é bastante significativo, não é um fato isolado, é o reconhecimento de que as pesquisas que começam a se desenvolver têm competência e peso acadêmico suficientemente fortes para figurar e se destacar mesmo em um campo como o da filosofia, que por vezes pode parecer excessivamente hermético e até conservador.

Para abordar este assunto, seguirão então seis pequenas subdivisões: uma breve contextualização sobre a procedência deste discurso; uma introdução onde se questionam os objetivos e métodos no fazer filosófico; um comentário sobre três principais pré-requisitos para que alguém pudesse se tornar o diretor de uma universidade em que a filosofia era ensinada e desenvolvida; a noção de linhagem que é de extrema importância para se entender a forma como acontece a transmissão do conhecimento neste contexto; um questionamento sobre o dogmatismo ou não dogmatismo; e, por fim, algumas observações sobre a relação entre budismo, filosofia e prática.

\section{Da genealogia}

Within the expanse of spontaneous presence is the ground for all that arises. Empty in essence, continuos by nature, it has never existed as anything whatsoever, yet arises as anything at all. (Longchen Rabjam, 2001, p. 3)

Para darmos início a este discurso, faz-se importante enfatizar que, como é sabido, o budismo e a filosofia que dele surgiu são extremamente ricos e variados; existem muitos "budismos" e muitas "filosofias", por isso me parece ser relevante salientar que, por mais que nesta narrativa haja uma tentativa de se falar de forma mais abrangente sobre este tipo de pensamento filosófico, cada escola budista, cada ramificação destas escolas e mesmo cada filósofo, trazem contributos muito singulares e que frequentemente entram em conflito uns com os outros, como parece natural acontecer nos mais variados campos de conhecimento humano. Assim sendo, parece relevante mencionar que o solo subjacente a este texto vem de uma formação centrada fundamentalmente no budismo tibetano. Todavia, faz-se também necessário dizer que, particularmente no contexto filosófico, mas não só, esta tradição veio, e nunca deixou de se nutrir, do pensamento de filósofos indianos como Nāgārjuna, Dharmakīrti, Candrakīrti, Śāntarakṣita etc. No século VIII, quando 
o Rei tibetano Trisong Detsen convida o diretor na Universidade de Nalanda, Śāntarakșita, para estabelecer residência no Tibete e organizar a estrutura monástica para o estudo da filosofia e das práticas budistas, começa a ser formado um grupo de tradutores e de pensadores extremamente qualificados, e é a partir daí que a filosofia budista de origem tibetana se desenvolve de forma mais consistente; ela efetivamente se fortalece e se torna o solo para o florescimento de grandes outros filósofos, como Je Tsongkhapa (1357-1419), Künkhyen Longchenpa (1308-1364), Chöje Sakya Pandita (1182-1251), Je Gampopa Sönam Rinchen (1079-1153), e assim por diante. Foge ao escopo deste texto fazer um levantamento histórico da formação do pensamento filosófico budista no Tibete, esta contextualização é apenas para localizar melhor o leitor em relação ao universo de referências que embasam, ainda que de forma por vezes latente, tal discurso. Partamos então para a discussão sobre o filosofar budista, a sua motivação e os seus métodos.

\section{Das motivações e métodos do fazer filosófico}

Each and every one of us wants to be happy. What 'happiness' means, though, and exactly how we achieve it is a matter for debate. (Khyentse, 2012, p. 13)

Nos palcos da filosofia ocidental já se discute, há mais de 200 anos, se a chamada filosofia "oriental", neste caso específico a filosofia budista, poderia ser de fato chamada de filosofia. Vários são os argumentos a favor e contra e, grosso modo, poderíamos dizer que, entre os argumentos a favor, é possível afirmar que, enquanto uma tentativa de responder questões fundamentais sobre a existência, o conhecimento, a mente, os valores, a linguagem etc, de uma forma crítica e sistemática utilizando-se da argumentação racional, ela sem dúvida atende muitos modelos ocidentais. Aqueles que se colocam contra muitas vezes criticam o fato de ela ter aspectos tidos como religiosos, de ter uma proposta soteriológica, de ser dogmática etc. Neste breve texto, gostaria então de retomar alguns destes temas, pois acredito que ainda sejam relevantes no nosso contexto e que são capazes de alimentar esta discussão.

Para dar início a algumas destas questões, parece-me fundamental pensarmos na motivação, nos objetivos, ou mesmo nos métodos - pois, se estamos querendo estudar uma vertente do conhecimento utilizando-nos de métodos diferentes e tendo objetivos diferentes, será que estamos falando da mesma coisa? - que levaram à fundação de uma forma específica de utilização 
do discurso em que os processos de aquisição de conhecimento ${ }^{2}$ se dão por meio do estudo ${ }^{3}$ (s. śrutamayīprajñ̄ā), da reflexão crítica (s. cintāmayīprajñāa) e do cultivo contemplativo (s. bhāvanāmayīprajñā). ${ }^{4}$ Todavia, quando se fala nesta terceira etapa da metodologia budista, o cultivo contemplativo que, em outras palavras, é a meditação, grande parte dos acadêmicos ocidentais considera isso como algo fora do âmbito estritamente intelectual e, por assumir este posicionamento como correto, imediatamente descarta esta etapa da sua pesquisa, na maior parte dos casos sem experiência própria. Mas será que assumir tal posição, sem de fato compreender a fundo o que significa este "meditar" em seu próprio contexto, é uma atitude coerente? Parece ser fundamental alertar, ou relembrar, alguns daqueles que têm certo preconceito em relação a esta etapa do procedimento filosófico sobre o qual falamos aqui, sobre a importância da meditação, não como uma espécie de "prática mística", mas como um processo, ou dispositivo cognitivo, indispensável a tal filosofia quando abraçada em seus próprios parâmetros. Meditação, neste contexto específico, significa literalmente habituarmo-nos ao ponto de vista resultante dos processos anteriores de análise e contemplação. Em tibetano, meditação é sgom, que significa habituar-se, estar familiarizado, acostumado ou nyams su len $p a$, que é levar ao próprio cerne, i.e., incorporar a compreensão.

Quando, por exemplo, a filosofia budista divide a análise da verdade em dois níveis ${ }^{5}$ (s. dvasatya / t. bden pa gnyis), o da verdade absoluta/suprema (s. paramārtha-satya / $t$. don dam bden $p a$ ) e o da verdade relativa/ordinária (s. samvrti-satya / t. kun rdzob bden pa) - assunto crucial dentro deste contexto filosófico -, de acordo com esta tradição, o discurso estabelecido para se falar sobre a verdade seria como um dedo que aponta para a lua, e não a própria lua, este discurso é um indicador que pode, no nível relativo, sugerir,

2 Como destaca Kapstein (2001, p. 25) este desenvolvimento progressivo da sabedoria é um modelo amplamente invocado na educação budista e reflete a progressão semelhante descrita na literatura Upanișat.

3 A terminologia em sânscrito será precedida pela letra "s", e foi adotado o sistema de transliteração IAST (International Alphabet of Sanskrit Transliteration). As nomenclaturas em tibetano serão escritas de acordo com método de transliteração desenvolvido pelo tibetologista Turrell V. Wylie, e quando estiverem entre parênteses serão precedidas pela letra "t".

4 Pode se falar também em duas outras etapas posteriores: a quarta etapa, em que se adquire confiança naquilo que já é resultante da meditação (s. niscayamayīprajñā), e em uma quinta etapa, que é a completude total (s. adhiprajñā).

5 Para mais detalhes sobre a questão das duas verdades, vale a pena ver a exposição de Chandrakirti em "Introduction of the Middle Way". Boston, London: Shambhala Publications, 2004, pp. 165-187. Vale lembrar que esta é uma questão fundamental dentro do contexto buddhista, e foi tratada pela maioria de seus filósofos. Para uma explicação mais focada na tradição Yogachara, vale verificar o artigo de Dan Lusthaus, "The Two Truths in Early Yogācāra". Journal of Buddhist Studies, Vol. VII, pp. 101-152, 2010. O qual também pode ser encontrado na internet, em http://www.academia.edu/225209/The_Two_Truths_ Sa_v_ti-satya_and_Paramartha-satya_in_Early_Yogacara. 
ou literalmente apontar, como se pode chegar à compreensão da verdade absoluta, a qual está além da linguagem discursiva. Quando nos dispomos a nos tornar especialistas nesta área, é difícil nos esquivarmos de um processo que é condição sine qua non dentro do seu próprio contexto; ainda mais se quisermos de fato compreender um assunto nos parâmetros em que ele foi criado, e não apenas usar os nossos próprios modelos anteriores e tentar, de maneira forçada, fazer com que ele se encaixe naquilo em que previamente acreditamos.

É claro que não somos tão ingênuos a ponto de pensar que podemos nos “despir" de nós mesmos e que somos capazes de compreender uma cultura tão distinta da nossa sem que a nossa leitura seja permeada pelos nosso próprio contexto cultural, linguístico e assim por diante, mas é também importante ressaltar que o budismo tem uma história de mais de 2.500 anos, ao longo dos quais a filosofia foi sendo desenvolvida e comentada em contextos culturais dos mais diversos; mas, mesmo ganhando "sabores" diferentes, isso não quer dizer que se possam esquecer aspectos fundamentais dos processos epistemológicos e mesmo hermenêuticos que são propostos dentro desta tradição.

Dentro deste contexto sobre as formas como as várias culturas foram incorporando esta tradição, e pensando particularmente no contexto brasileiro, mas sabendo que situação semelhante ocorre também em outros lugares, poderíamos pensar, a título de exemplo, em um dos preconceitos acadêmicos que já vi tantas vezes em discussões sobre o assunto, que é a forma distorcida como muitos veem a contribuição de grandes especialistas tibetanos (entre outros) que, pelo fato de também serem reconhecidos por suas qualidades descritas como espirituais, são tidos como pensadores de menor importância. O fato de serem vistos como representantes de uma tradição chamada de espiritual, de maneira alguma diminui a competência e o conhecimento que eles têm sobre a tradição filosófica em que foram rigorosamente formados desde a mais tenra idade. Além disso, não se pode menosprezar o fato de que, particularmente nos dias de hoje, e mais especificamente ainda no contexto tibetano depois da revolução cultural chinesa, eles foram adquirindo conhecimento embebidos em contextos culturais dos mais diversos, em lugares como a Inglaterra, a França, os Estados Unidos etc., a ponto de se tornarem interlocutores de altíssimo nível mesmo entre pensadores de culturas muito diferentes do berço original aonde foram inicialmente educados, e este quadro torna-se cada vez mais evidente nas novas gerações, que estão sendo concomitantemente formadas nos moldes ocidentais, e desde muito jovens 
começam a viajar pelo mundo, como é o caso de Dilgo Khyentse Yangsi Rinpoche, Yongey Mingyur Rinpoche, Karmapa Ogyen Trinley Dorje etc.

Para citar um exemplo, ainda da antiga geração, basta verificar o livro "The Universe in a Single Atom", do Dalai Lama (2005), onde é possível apreciar a propriedade com que ele fala sobre a convergência da ciência moderna com a espiritualidade, e a capacidade que tem de dialogar com Descartes, Karl Popper, neurocientistas etc. O que se quer ilustrar com este comentário é que não parece apropriado a um pesquisador descartar grandes expoentes desta forma de pensamento por desconhecimento da dimensão daquilo que tais personalidades representam. Tibetologistas, e mesmo especialistas de outras tradições budistas, dos mais diversos países utilizam citações do Dalai Lama, entre outros professores e mestres budistas, como referência para dar legitimidade às suas propostas, teorias e discursos, e indago-me por que é que aqui no Brasil, assim como em outros lugares, muitos de nós ainda nos comportamos de maneira tão conservadora. Lembrando ainda que mestres como Nāgārjuna, Tsongkhapa, entre tantos outros, são todos considerados mestres "realizados" - falarei desta questão mais adiante - com qualidades vistas como espirituais, e que nem por isso deixam de figurar entre os trabalhos feitos no Brasil, e é por isso que parece um tanto contraditório ignorar os representantes com qualidades similares que estão aqui vivos e presentes nos dias de hoje. Posto isso, que parece ser um tópico particularmente importante entre aqueles que querem estudar a filosofia budista, vamos falar então de forma direta sobre o "embate" entre estas maneiras específicas de filosofar.

De forma geral - e não digo que não há excessões, e vou falar sobre algumas delas -, a filosofia ocidental contemporânea é frequentemente vista como tendo um fim em si mesma. A filosofia budista, em contrapartida, muito embora se comporte de forma similar - em termos de crítica, sistematicidade, racionalidade - e dedique-se a questões semelhantes, tem um caráter bastante pragmático, i.e., a filosofia é apenas um meio, e não um fim em si mesma. O filósofo budista, em sua grande maioria, propõe-se a expor um sistema de pensamento que visa orientar aquele que se coloca em contato com ele, sobre como se engajar na investigação de processos mentais, fenomenológicos etc., e de como, a partir desta imersão, transformar a própria mente. O processo de transformação da mente e de investigação dos fenômenos é a principal função da filosofia, e esta nada mais é do que um trampolim para um caminho que leva à eliminação da ignorância e de todo sofrimento que dela provém.

Sem uma aplicação direta junto ao estudo, à reflexão crítica e ao cultivo contemplativo daquilo que está sendo exposto e proposto, a filosofia budista deixa de ter sentido ou, pelo menos, deixa de cumprir a sua verdadeira razão 
de existir dentro do seu próprio contexto. Isso não quer dizer que não existam muitos filósofos ocidentais com uma preocupação similar à dos budistas, especialmente durante o período helenístico, mas não só. A título de exemplo, entre muitos outros, poderíamos citar Sócrates, que vivia aquilo que "pregava" e acreditava neste aspecto pragmático, e em certo sentido terapêutico, do filosofar. Ou ainda Epicuro, que exortava o exercício da filosofia, a qual considerava "uma disciplina cuja meta era justamente tornar feliz o homem que a pratica" (2002, p. 14). Para ele, esta prática deveria ser cultivada durante todo o transcurso da nossa existência, "desde a mais tenra juventude até a idade mais avançada. Após esse exórdio, o filósofo passa a transmitir para o discípulo aqueles tópicos que considera essenciais para esta busca permanente da felicidade" (p. 15).

Mas isto não é necessariamente verdadeiro no caso da filosofia ocidental como um todo, a qual, em parte, está mais preocupada com os processos "especulativos" e conceituais que têm um fim em si mesmo do que com a aplicabilidade prática na vida das pessoas. ${ }^{6}$ Quando Deleuze e Guattari descrevem a filosofia como "a arte de formar, de inventar, de fabricar conceitos" (1992, p. 8) - sem querer dizer que os conceitos sejam desprovidos de qualidades capazes de transformar aquele que tem acesso a eles -, parece que com tal afirmação fica implícito que o foco, ou a principal motivação do fazer filosófico, não é exatamente o mesmo nos dois casos. Não que tenhamos que concordar com a proposta de Deleuze/Guatari, mas parece evidente que este também seja um reflexo de determinada maneira de se pensar a filosofia contemporânea no Ocidente.

Dentre os filósofos ocidentais contemporâneos que tentaram de maneira bastante ativa resgatar uma forma de filosofar com aspectos efetivamente pragmáticos, em muito similares ao filosofar budista, podemos destacar Pierre Hadot. Tendo falecido em 2010, esse filósofo francês passou muitas décadas empenhando-se em reler a tradição da filosofia clássica, a qual, segundo Kapstein (2001, p. 7), tenta restaurar a relação entre pensamento e ser, dentro do universo filosófico inicialmente proposto pelos gregos. Ao criar o conceito de "exercício espiritual", Hadot (1995, p. 107) sugere que a filosofia vista por esta perspectiva reaparece em seus moldes originais, não como uma construção teórica, mas sim como um método para treinar as pessoas a viverem e a verem o mundo de uma nova maneira, a filosofia serviria então como uma tentativa

6 Não ignorando o fato de este ser um tema este amplamente discutido entre os próprios filósofos ocidentais, e retomado por Jürgen Habermas, por exemplo, em que se fala da "filosofia de vida" e da "filosofia em seus moldes profissionais", e também a relação entre ambas e a complementaridade entre elas. 
de transformar a humanidade. Ele afirmava ainda que um filósofo deveria ser avaliado pela maneira como vive, mais do que por aquilo que simplesmente escreve.

De forma similar, o filosofar budista é uma prática que deve ser aplicada para ter sentido e não ser apenas uma fonte de conhecimento que pode nos ajudar a acrescentar informações, mas não necessariamente proporcionar efetivas transformações em todo o nosso processo de compreensão do mundo e de nós mesmos. Claro que não somos ingênuos a ponto de acreditar que a análise filosófica tal qual estabelecida no Ocidente, pelo seu próprio processo analítico, não leve a transformações, mas, sem os processos de estudo, de reflexão crítica, e de cultivo contemplativo, a filosofia budista é desprovida de significado, caso seja abordada em seu próprio berço. A função da filosofia, neste caso, é encorajar o desenvolvimento de faculdades que nos capacitem a investigar as aparências dos fenômenos e penetrar na realidade deles. Parece razoável a afirmação de que, para se penetrar, de fato, na "realidade dos fenômenos", não é suficiente nos basearmos unicamente na dimensão intelectual desta realidade, pois isso nos restringiria a uma interpretação de caráter quase que exclusivamente especulativo; para podermos efetivamente perceber a realidade em todas as suas nuances, parece ser indispensável ter-se também uma dimensão experiencial daquilo que nomeamos realidade, e é isso que se abrange na proposta de reflexão crítica, e ainda mais profundamente na de cultivo contemplativo/meditação, que estão arraigadas a esta tradição filosófica.

De qualquer forma, não devemos ignorar o fato de que os estudos sobre o budismo e a sua filosofia podem ser abordados das mais diversas maneiras, dependendo da predisposição de cada um. Se uma pessoa deseja estudar o budismo como uma filosofia racional "livre" dos vínculos ditos/vistos como "espirituais"/"religiosos" - como acontece em alguns dos estudos acadêmicos ou mesmo com não especialistas -, e se focar apenas na dimensão tida como filosófica nos "parâmetros ocidentais", o budismo também pode ser abordado desta forma; muito embora seja importante relembrar que esta é uma perspectiva pessoal do investigador, que o afasta de um contexto mais amplo. Ao analisarmos o conteúdo textual da filosofia budista, facilmente podemos verificar que esta tem as qualidades necessárias para ser vista como um sistema filosófico estruturado e lógico capaz de figurar nas "augustas salas" da filosofia ocidental, pelo menos enquanto uma forma organizada de pensamento que investiga os fenômenos do mundo. Sem dúvida são filosofias diferentes que devem ser vistas em suas especificidades, mas ambas também se utilizam da razão para investigar questões de caráter semelhante. 
Ainda dentro desta discussão, é importante ressaltar que a filosofia tal qual vista no Ocidente tornou-se o critério de avaliação sob o qual outros sistemas de investigação serão julgados, e é a partir destes parâmetros que a filosofia budista é "levada ao tribunal". Mesmo filósofos ocidentais "bem intencionados" em tentar provar a legitimidade da filosofia budista ${ }^{7}$ tentam demonstrar que as formas budistas de investigação racional podem ser tão críticas e sofisticadas quanto o modelo ocidental, e que as questões elaboradas são similares e, por isso, dignas de serem estudadas. Esta tentativa pode ser problemática, pois, ao avaliarmos a filosofia budista a partir de um parâmetro distinto do seu próprio, inevitavelmente caímos em distorções não só da filosofia, mas do budismo como um todo.

\section{Das qualidades}

Without someone at the helm, the boat will never reach the other side.

Even for one in whom all virtuous are complete, without a teacher, there is no end to existence. (Gạ̣ḍavyūha Sūtra. In: Dorje, 2011, p. 9)

Podemos pensar ainda em um outro aspecto fundamental, característico do fazer filosófico budista, que é frequentemente negligenciado por parte dos pesquisadores, a ética comportamental. A conduta do filósofo é colocada em pauta para que se possa avaliar a qualidade deste, o que é relativamente similar à proposta de Hadot vista anteriormente. Para entendermos melhor como isso funciona, podemos tomar o exemplo dos pré-requisitos necessários para que um erudito se tornasse diretor de uma universidade budista, como Nālandā. Como nos aponta Kongtrul (2011), para que um filósofo e erudito ocupasse a posição de diretor-geral da Universidade, como foi o caso de Śāntarakṣita, fazia-se necessário ter três qualidades fundamentais: ser extremamente erudito, ter uma conduta impecável e, além disso, ser uma pessoa agradável e de "bom caráter". Mas podemos nos perguntar o que exatamente esta última condição significa. Dentro da estrutura filosófica do budismo, além do conhecimento, como forma de transformação, é necessário que a pessoa que ensina e escreve sobre tal filosofia tenha uma compreensão plena daquilo que diz, além de possuir as mesmas qualidades por ela apresentadas, o que em tibetano é chamado rtogs pa. Esta palavra é relativamente complicada

7 E aqui não me parece ser adequado citar apenas alguns nomes, pois uma discussão de caráter abrangente poderia correr o risco de se tornar algo pessoal. 
de ser traduzida em português, mas o sentido mais próximo seria "tornar-se completamente ciente" de alguma coisa, "compreender clara e plenamente", ou simplesmente "entender". Em inglês, a palavra que é usualmente adotada para a tradução é "realize", porém "realizar" para nós não possui exatamente as mesmas acepções. Em contrapartida, se em português optarmos simplesmente por "compreender", isso poderia nos conduzir a um entendimento muito "simplista" da palavra, permitindo interpretações errôneas que pudessem levar a uma compreensão deste termo em seu aspecto meramente intelectual, o que não é sempre condizente com o vocábulo empregado em tibetano e a importância dele dentro da filosofia, na qual a teoria também é "compreendida", "realizada", na prática.

Vale rapidamente recordar que, em seus primórdios, a palavra theoria ${ }^{8}$ tinha como significado contemplar, especular, observar. Hoje, quando falamos em teoria, quase que automaticamente associamos a algo oposto à prática, mas este não era o sentido original tal qual apresentado por Aristóteles, por exemplo, para quem a theoria era a mais valiosa das práticas. ${ }^{9}$

Sendo assim, e voltando à nossa tentativa de entender as qualidades necessárias a um filósofo budista, uma vez que não somos capazes de saber o que efetivamente acontece na mente de outras pessoas - neste caso, se têm o nível de "rtogs pa", i.e., uma compreensão plena -, podemos ter acesso apenas àquilo que nos chega diretamente por meio dos sentidos e da cognição, a única forma possível de se tentar saber se a pessoa era realmente um filósofo com esta qualidade de "realização/compreensão" seria se ela efetivamente se comportasse como tal. Por este motivo, era tão importante a questão do caráter/ conduta daquele que ocupava o principal posto da Universidade. Dentro dos parâmetros da filosofia no Ocidente, e mesmo nas instituições universitárias, este tipo de questão sequer é colocado, a não ser que se faça algo realmente "perverso", ou "fora da lei", e seja “descoberto". Mas, para nos aproximarmos do pensamento filosófico budista, de forma condizente com os seus próprios paradigmas, este também é um aspecto fundamental, que não pode deixar de ser considerado quando se pensa na própria motivação do fazer filosófico, como foi dito anteriormente.

8 Com grafia grega $\theta \varepsilon \omega p i ́ a$, que se inicia pela letra Teta $\Theta$ a qual, em alguma religiões, serve como representação do espírito.

9 Kapstein escreve: "[...] perhaps to some degree echoing Heidegger, (Hadot) stresses our mistaken tendency to read theoria as synonymous with what we now mean by 'theory', and accordantly to position theoria over and against what we call 'practice'. For Hadot, theoria in Aristotle's sense is itself the most highly valued practice; it is, in fact, that practice through which human beings may come to participate in an activity that is characteristically divine" (2001, p. 9). 


\section{Da linhagem}

... with regard to giving the profound teachings on the actual condition of things, teachers who have no realization cannot make the ultimate experience and realization develop in their disciples' mindstreams. (Dorje, 2011, p. 21)

Outra característica muito específica da filosofia budista, que envolve as tradições de transmissão de conhecimento, é a chamada linhagem. Quando falamos em linhagem, referimo-nos tanto àquilo que é transmitido, quanto às pessoas envolvidas nesta transmissão, a forma como isso ocorre, o local e o momento em que isso se dá. As linhagens são particularmente importantes, pois se um determinado conceito não for transmitido e recebido de forma clara e precisa, evitando ao máximo as inúmeras interferências, deturpações e filtros decorrentes da passagem da informação de uma mente a outra (onde se $\operatorname{diz} \mathrm{A}$, e se entende A', ou B, ou C etc.), após algumas gerações, tanto os ensinamentos que foram passados há mais de 2500 anos, quanto aqueles que estão sendo transmitidos em nossos dias, estariam completamente distorcidos. Por isso, dentro deste contexto de linhagem, particularmente de uma linhagem oral ininterrupta, tão significativo no universo do pensamento budista indotibetano, é fundamental sabermos quem foi o autor de determinado texto, para quem foi passado, por quantas gerações foi passado, como e onde isso aconteceu, sendo indispensável a transmissão direta e presencial de um para o outro.

Este aspecto, quase que incompreensível para grande parte das tradições filosóficas tais quais estabelecidas no Ocidente, e mesmo em outros contextos no Oriente, pode parecer "alienígena" para a maioria de nós, principalmente por não termos sido ensinados a nos relacionar assim com os textos que consultamos, lemos e interpretamos; mas, dentro de uma perspectiva estritamente lógica, parece-nos quase que "natural" constatar que quanto maior for a proximidade que tivermos com o autor do texto, mais fácil será compreender aquilo que ele tenta expressar, particularmente quando se trata de uma compreensão não apenas intelectual, mas também experiencial.

Como parece natural, é comum termos maior afinidade com uma determinada forma de pensar e nos seja mais fácil "entender" alguns autores do que outros, justamente por este processo de empatia, mas até que ponto podemos ter certeza de que aquilo que estamos lendo e reinterpretando em nossas mentes está minimamente próximo daquilo que o "outro" tentou transmitir? Isso não quer dizer que temos que simplesmente receber a informação da forma mais acurada possível, e aceitá-la sem questionar, muito 
pelo contrário, como foi dito, a análise e a contemplação são aspectos sine qua non.

Quão bom não seria se pudéssemos ter acesso direto a Heidegger, Kant, Nietzsche e assim por diante, se pudéssemos nos sentar com eles, esclarecer dúvidas, fazer as perguntas que quiséssemos sem "intermediários", tudo isso "em primeira mão". Mas, infelizmente, não podemos, não podemos nem sequer ter acesso a "detentores" diretos daquela forma de pensar, i.e., de alunos diretos que absorveram e se identificaram profundamente com o que lhes havia sido exposto de tal forma que seria quase como se tivesse sido elaborado por eles mesmos. E estes alunos tivessem outros alunos, e assim sucessivamente até os dias de hoje, tornando possível ainda se ter acesso direto a estes "representantes". Todavia, isso não acontece, e para alguns tal especulação pode parecer "sem sentido", "mística", ou qualquer outro nome que se queira dar. No entanto, o fato de culturalmente termos nos acostumado a determinados tipos de comportamento não impede que outras tradições se comportem de forma distinta, como é de bom senso geral.

Como se sabe, o conhecimento é construído a partir de um entendimento anterior, e não podemos eliminar as nossas acepções prévias engendradas pela época em que nascemos, o contexto em que vivemos, as nossas circunstâncias pessoais etc. Mas, quando estamos cientes das nossas próprias limitações, parece ser mais fácil entender diferenças tão profundas como a importância da linhagem em uma tradição filosófica, lembrando que pessoas extremamente competentes, lúcidas e bem dotadas intelectualmente, efetivamente se engajaram nestas atividades e mantiveram tal tradição, e que as mesmas devem ter motivos razoáveis para se comportarem desta forma; sendo assim, talvez este aspecto por vezes negligenciado entre os acadêmicos brasileiros pudesse ser também levado em consideração, e não deixado de lado como se fosse apenas uma "parte indesejável" de um universo que se pretende investigar.

\section{Do dogmatism}

Monks, just as the wise accept gold after testing it by heating, cutting and rubbing it, so are my words to be accepted after examining them, but not out of respect [for me]. (Buda Śakyamuni. In: Dalai Lama, 1999, p. 169) ${ }^{10}$

10 O texto acima é uma referência frequente na literatura budista tibetana, e é citado a partir do comentário sobre o Kālacakra (t. (dus kyi 'khor lo) presente no Vimalaprabhā. Além disso, ele também faz parte do cânone Pali. 
Outra questão que parece ser relevante rediscutir-mesmo em um momento em que muitos especialistas já superaram tal preconceito - é um possível dogmatismo que, por vezes, é apontado como mais um fator diferencial entre a filosofia budista e a ocidental. Em geral, os filósofos ocidentais proclamam-se como pensadores livres da necessidade de seguir qualquer doutrina previamente estabelecida para assim desenvolver as suas investigações, ao passo que, no caso da filosofia budista, haveria a necessidade de se seguir um determinado "cânone fixo e limitado" para que os posicionamentos dos filósofos fossem aceitos, o que a tornaria uma filosofia dogmática. Esta afirmação é duplamente questionável, tanto por parte da filosofia budista quanto da ocidental.

Quanto à ocidental contemporânea, por mais que idealmente o filósofo possa ter liberdade total para expressar os seus pensamentos, foge ao meu conhecimento qualquer filósofo que efetivamente tenha elaborado uma linha de pensamento, e a legitimado dentro da sua área ou mesmo de outras áreas do conhecimento, que não tenha se utilizado de muitos dos inúmeros referenciais previamente reconhecidos dentro do seu campo de investigação. No caso da filosofia budista, muito embora a postura dos pensadores em relação à questão da autoridade dos textos seja bastante complexa, sem dúvida na maior parte dos casos se trabalha dentro das fronteiras de um universo textual no qual a opinião de filósofos do passado é relevante; mas daí a se afirmar que devido a este fato a filosofia budista seja dogmática, seria um tanto quanto simplista, para não dizer ingênuo.

Como afirma o especialista Cabezón (2010), ${ }^{11}$ o cânone das escrituras budistas é tão rico e diverso que um pensador é capaz de encontrar autenticação textual para justificar praticamente qualquer ponto de vista que ele queira abraçar. Dentro deste contexto, em que uma determinada opinião pode ser apoiada ou combatida por fontes textuais igualmente válidas, tornarse-á necessário aos acadêmicos procurarem outras formas para validarem os seus pontos de vista, como é o caso da argumentação lógica, amplamente difundida dentro dos moldes estabelecidos pela filosofia budista. Além disso, assim como os filósofos ocidentais, também os filósofos budistas criticam outros pensadores quando acham isso justificável, o que seria impossível se a filosofia budista fosse um simples dogmatismo.

11 Este trabalho citado de José I. Cabezón, "Buddhism Philosophy or Practice", foi parte de uma apresentarão oral realizada por ele em 2010 no encontro anual da AAR (American Academy of Religion), que me foi dada pessoalmente na forma impressa durante meu pós-doutorado na UCSB (University of California Santa Barbara). Infelizmente, não há outras referências bibliográficas para que o leitor possa ter acesso direto ao material, mas, caso haja interesse, podem me contactar diretamente. 
O já mencionado Tsongkhapa, fundador da escola Gelugpa, que bebeu das mais variadas fontes de tradição budista e trabalhou particularmente com os textos de Atisha, ao se dedicar à explicação dos dois níveis, "definitivo" e "provisório", das elaborações sobre a realidade tal qual ela é, afirma que a questão sobre o que era uma visão definitiva ou provisória nos discursos de Buda não poderia ser estabelecida ao "confiarmos" exclusivamente nas escrituras; sendo que uma visão correta sobre a realidade só poderia ser estabelecida ao nos basearmos em um raciocínio e análise perfeitos (Cabezón, 2010). ${ }^{12}$

Sendo assim, a afirmação de que a filosofia ocidental é absolutamente livre e a budista dogmática não é nada mais do que um posicionamento pouco condizente com a forma como ambas as filosofias se desenvolvem. Como se sabe, é impossível que nós, seres humanos, de qualquer nação, não sejamos nutridos e guiados por paradigmas inconscientes - ou mesmo conscientes - que estão vinculados aos modelos culturais, históricos e contextuais que moldam, ao longo dos tempos, a nossa maneira de pensar; assim sendo, ambas as filosofias estão limitadas por este condicionamento humano, que é geral, e não de uma cultura em particular.

O dogmatismo mataria a única razão de ser do filosofar budista, pois inviabilizaria toda e qualquer realização/compreensão que só se torna possível por um processo de investigação pessoal, capaz de cumprir o verdadeiro objetivo desta filosofia, libertar-nos da ignorância inerente à existência cíclica.

\section{Do budismo e sua filosofia}

O Gentle Sir, to make your disenchantment grow with this samsara, source of many pains - desires frustrated, death, ill health, old age - please heed its defects, even just a few. (Nāgārjuna, 2005, p. 53)

Um último ponto que gostaria de levantar neste breve comentário é que, algumas vezes, referi-me à filosofia budista apenas como budismo, e viceversa. O motivo para tal forma de expressão é simples: o filosofar budista, assim como acontece com algumas das propostas filosóficas ocidentais citadas acima, é um processo que tem a finalidade explícita de transformar aqueles que se dedicam a tal atividade. Neste sentido, muito embora a filosofia

12 Devemos considerar ainda a importância da prática dos duelos filosóficos (debates) que são até hoje parte integrante e fundamental da formação acadêmica nas universidades budistas. Para uma maior compreensão sobre o assunto, ver Dreyfuss (2003). 
budista seja apenas uma parte deste universo, algumas vezes a filosofia se funde tão completamente a este todo mais abrangente, que é difícil separálos. No entanto, não se deve esquecer que, dentro do contexto escolástico em que a filosofia budista é apresentada, particularmente no universo tibetano, a fé é tida como algo secundário, dado que o desenvolvimento da sabedoria é a meta principal desta tradição. Ainda que por vezes possamos falar em budismo e filosofia budista de forma semelhante, o que poderia fazer com que alguns acreditassem que apenas a "fé"13 estaria envolvida em ambos os casos, é justamente o contrário que aproxima as duas coisas, é a sabedoria e o questionamento crítico que orienta tanto o budismo quanto a sua filosofia.

Posto isso, encerro então esta breve reflexão que visa apontar, de forma bastante concisa, alguns dos pontos que considero relevantes para o entendimento da filosofia budista por entre o papel hegemônico que a filosofia "ocidental" exerce em nossa forma de pensar e ver o mundo. Fica então a aspiração de que estes comentários possam colaborar para ampliar o debate, e de que seja possível se fazer uma reavaliação de alguns posicionamentos anteriormente aceitos. Encerro então lembrando mais uma vez que, sem os processos de reflexão crítica e de cultivo contemplativo/meditação, que são parte integrante desta tradição filosófica, a mera argumentação conceitual e linguística da qual nenhuma das filosofias pode escapar é, em termos budistas, insuficiente.

\section{Referências}

CABEZÓN, José I. "Buddhism: Philosophy or Practice". Congresso AAR, 2010, USA.

DALAI LAMA. "The Universe in a Single Atom. The Convergence of Science and Spirituality". New York: Three Rivers Press, 2005.

DALAI LAMA. "Consciousness At The Crossroads: Conversations With The Dalai Lama On Brain Science And Buddhism". Ed. Zara Houshmand, B. Alan Wallace, Robert B. Livingston. Ithaca, New York: Snow Lion Publications, 1999.

DELEUZE, G., GUATTARI, F. “O que É a Filosofia”. Tradução: Bento Prado Jr. e Alberto Alonso Muñoz. São Paulo: Ed. 34, 2010 ( $3^{\text {a }}$ Edição - $1^{\text {a }}$ Reimpressão 2013). Edições anteriores: 1992, 1997.

13 O entendimento do termo "fé" no budismo deve ser visto como algo mais próximo daquilo que nós chamamos de confiança, a qual é desenvolvida por meio do escrutínio exaustivo das exposições filosóficas, como fica claro nos versos de Buda supracitados. 
DORJE, Jigdrel Yeshe (Dudjom Rinpoche). "A Torch Lighting the Way to Freedom: Complete Instructions on the Preliminary Practices". Tradução do Padmakara Translation Group. Boston \& London: Shambhala Publications Inc., 2011.

DREYFUS, B. J. Georges. "The Sound of Two Hands Clapping. The Education of a Tibetan Buddhist Monk". Berkeley/Los Angeles/London: University of California Press, 2003.

EPICURO. "Cartas sobre a Felicidade". Tradução e apresentação: Álvaro Lorenzini e Enzo Del Carratore. São Paulo: Ed. UNESP, 2002.

FERRARO, G. “'Verdade ordinária' e 'verdade suprema' como bases dos ensinamentos budistas no pensamento de Nāgārjuna". Orientação: Leonardo Alves Viera. Universidade Federal de Minas Gerais, 2012.

HADOT, Pierre. "Philosophy as a Way of Life: Spiritual Exercises from Socrates to Foucault". Oxford: Blackwell Publishing Ltd, 1995.

KAPSTEIN, T. Matthew. "Reason's Traces: Identity and Interpretation in Indian and Tibetan Buddhist Thought. Boston: Wisdom Publications, 2001.

KHYENTSE, D. J. "Not for Happiness: A Guide to the So-Called Preliminary Practices". Boston \& London: Shambhala Publications Inc., 2012.

NĀGĀRJUNA. "Letter to a Friend". Tradução do Padmakara Translation Group. Ithaca, New York / Boulder, Colorado: Snow Lion Publications, 2005.

SAID, E. W. "Orientalismo. O Oriente como Invenção do Ocidente". Tradução: Rosaura Eichenberg. São Paulo: Companhia de Bolso, 2012 ( $3^{\text {a }}$ Reimpressão). Edições anteriores: 1978, 1995, 2003.

Vídeo

KONGTRUL, D. (Rinpoche). "Examining the Two Truths II". Shedra 2011. Madhyamākalaṃkāra. Year Two - Śāntarakșita's Adornment of the Middle Way. Boulder (USA): Wisdom Productions - Mangala Shri Bhuti, 2011. 